\title{
POSSIBILIDADES \\ DE INTERPRETAÇÃO \\ DO CONTEÚDO SIMBÓLICO \\ DA ARTE GRÁFICA GUARANI
}

Fernanda Bordin Tocchetto ${ }^{1}$

Este trabalho compreende os resultados finais da pesquisa, realizada com o apoio da Fundação de Amparo à Pesquisa do Rio Grande do Sul, cujo objetivo corresponde à interpretação do conteúdo simbólico da arte gráfica das vasilhas cerâmicas dos Guarani pré-coloniais.

A primeira etapa foi desenvolvida através do levantamento de materiais cerâmicos de sítios arqueológicos Guarani que apresentassem desenhos geométricos pintados e da comparação destes com a arte gráfica Asuriní e Kayabí, grupos Tupi do Xingu, cujos significados foram intensamente documentados por Müller (1990) e Ribeiro (1986).

A analogia etnográfica foi aplicada na tentativa de interpretação do conteúdo dos signos gráficos da cerâmica arqueológica. No decorrer da pesquisa, no entanto, a relação analógica apresentou limites que foram tornando-se nítidos: os signos usados como expressão simbólica são únicos e específicos da sociedade que produz. Mesmo entre grupos que possuam afinidades culturais, como os Asuriní, Kayabí e Guarani, e ainda semelhanças entre aspectos formais dos desenhos geométricos, o significado que é atribuído a estes é construído diferentemente, a relação entre expressão (forma) e conteúdo (significado) é próprio do contexto sócio-cultural de cada sociedade.

1 Antropóloga, pesquisadora em Arqueologia do Museu Joaquim José Felizardo (Secretaria Municipal da Cultura de Porto Alegre, RS).

Estudos Ibero-Americanos. PUCRS, v.XXII, n.1, p. 27-45, junho, 1996 
Em vista disto e dando continuidade ao projeto, realizei o levantamento de narrativas míticas Guarani buscando, com isso, elementos que possibilitassem a leitura simbólica dos signos gráficos.

Os desenhos geométricos pintados foram reunidos na bibliografia arqueológica, principalmente nos trabalhos de síntese, e nas vasilhas inteiras ou em grandes fragmentos destas armazenadas no Centro de Estudos e Pesquisas Arqueológicas da PUCRS, no Laboratório de Arqueologia da UFRGS e no Museu de Arqueologia do Rio Grande do Sul (o material arqueológico é proveniente de sítios do RS, muitos sem indicação da sua procedência ou qualquer outra informação).

\section{Considerações sobre a arte gráfica e os significados culturais}

"(...) a arte gráfica, em qualquer de suas modalidades, expressa significados culturais" (Vidal e Silva, 1992: 284).

Estudos antropológicos das últimas décadas no interior das sociedades indígenas afirmam que as manifestações artísticas expressadas através da pintura do corpo e de diversos objetos da cultura material dizem respeito "(...) à vida em sociedade, ao modo como os indivíduos são classificados e como devem ou podem se relacionar entre si, com a natureza e com o cosmo" (idem, p. 284).

As representações gráficas indígenas são produzidas por artesãos locais e compartilhadas por toda a comunidade, pois são imagens que todos conhecem. As experiências cotidianas, a maneira de estar no mundo e de pensar sobre este, Os valores tradicionais, transformam-se em uma linguagem visual através dos $\operatorname{signos}^{2}$ gráficos produzidos e reproduzidos pela coletividade. A arte, como "expressão visual sintética de uma 'visão de mundo'" (idem, p. 287), só pode ser estudada a partir da constatação das relações que se estabelecem com os domínios sócio-

2 "Um signo intenta representar, em parte pelo menos, um objetivo que é, portanto, num certo sentido, a causa ou determinante do signo, mesmo se o signo representar seu objeto falsamente. Mas dizer que ele representa seu objeto implica que ele afete uma mente, de tal modo que, de certa maneira, determine naquela gente algo que é mediatamente devido ao objeto. Essa determinação da qual a causa imediata ou determinante é o signo, e da qual a causa mediata é o objeto, pode ser chamada o Interpretante" (Santaella, 1990: 58, conforme Peirce). 
culturais, dentro do contexto geográfico e histórico no qual ocupa um espaço significativo. Cada sistema gráfico deve ser apreendido na sociedade a que pertence e relacionado aos demais aspectos da cultura, buscando os seus significados, seus conteúdos simbólicos.

Entre os Asuriní, por exemplo, Müller (1990) identificou um padrão de base - o 'tayngava' - presente na maioria dos desenhos pintados em diferentes suportes (corpo, objetos vários).

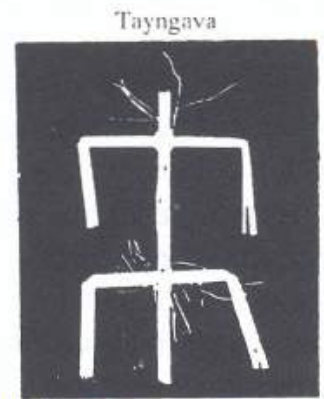

O padrão, 'tayngava' significa imagem, réplica do ser humano, boneco antropomórfico usado em rituais xamanísticos. O braço/perna é a unidade mínima de significação. (Müller, 1990: 243)

Undades minmmas de sagnificațas
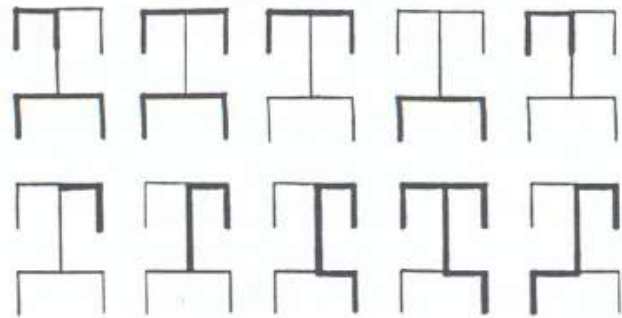

$\mathrm{O}$ boneco tayngava $\mathrm{e}$ unidades ninimas de significaçăo

Para os Asuriní, "(...) como elemento simbólico representado pelo boneco, o 'tayngava' representa o princípio constitutivo da categoria de humano (isto é, vivente, uno), compartilhado pelos espíritos, xamãs primordiais e animais da floresta" (idem, p. 244). O 'tayngava' expressa a noção abstrata do pensamento relativo à classificação dos seres na cosmologia e filosofia Asuriní. A autora mostra a carga simbólica da arte gráfica e trata-a como 'modelo reduzido', isto é, como uma forma sintética da visão de mundo, de conhecimento.

Outro exemplo é demonstrado por Vidal e Müller (1986) sobre os grupos Gê, onde os desenhos pintados sobre o corpo exprimem a concepção tribal de pessoa humana, a categorização social e outras informa- 
ções referentes à ordem social e cósmica. Entre os Xavante, as classes e categorias de idade, os grupos cerimoniais e linhagens diferenciam-se através da ornamentação corporal que comunicam, assim, mensagens relacionadas aos princípios que ordenam a vida social Xavante.

Já para os Kaxinawá, a palavra 'kene', que significa desenho, motivo, padrão, não serve para diferenciá-los "(...) se separar do mundo animal/natural/espiritual, mas para se distinguir de povos sem desenho, seus vizinhos. Animais podem ter 'kene kuin', 'vuxin' também, mas o desenho de outros povos nunca será ‘kuin' verdadeiro" (Lagrou, 1991: 140). 'Kene kuin' - desenho verdadeiro - é definidor da identidade Kaxinawá. Para estes o desenho - 'kene' - confere beleza e marca a pessoa.

A arte de pintar o corpo também constituía-se numa prática dos Guarani pré-coloniais. Expressões na língua Guarani, compiladas e traduzidas no século XVII pelo Pe. jesuíta Ruiz de Montoya, ${ }^{3}$ remetem à pintura corporal, infelizmente sem os seus significados: 'pintarfe la cara' = 'Ańẽmbo obá pŷni)'; 'pintarfe las piernas' = 'Ayee tŷmã pînŭ. Ańeẽ tỹmâ nĝuã.1.Pinãã'; 'pintarte los fienes' = 'Ayeatĭ açá. Ayeati gúã’; 'pintarfe los carrillos' = 'Ayeati pĭ qûã'. Ainda há outros verbetes quanto a quem executa a tarefa de pintar - 'quatiahára'; quanto ao ato de pintar - 'aiquatiá (bo); quanto ao resultado (pintado) - 'yquatia piré' (Montoya, [1639] 1876), e quanto aos atos de 'deshacer la pintura' - 'amboai' = 'aymôna' = 'amônegûa' = 'amboguâ' = 'amboyeog', 'desfigurar lo pintado' - 'am coguê' = 'aymô nâni' = 'am boyeog' e 'desbotar, quitar el color' 'amboguê' = 'aya patîmbóguê' (La Salvia e Brochado, 1989, cf. Montoya, op. cit.). Algumas expressões referem-se aos suportes não corporais onde se realizava a pintura ('quatiá'): 'cheaópini' = 'tengo ropa pintada, manchada (de PINI = pintura, mancha)'; 'camboyacaré chereya pepo' = 'pintar assi las ollas'. Outras aos motivos: 'yapepó yacaré' = 'olla pintada conforme a las mallas del lagarto (yacaré)'; 'cabafi rãmỹ ayapó yapepó' = 'pintar las ollas con unos agujeritos a modo de abisperas (de cabatĩ = tipo de abispas)'; ' gûa' = 'lista, raya atravessada, pintura';

3 O Vocabulario y Tesoro de la lengua Guarani do Pe. A. Ruiz de Montoya ([1639] 1876) contém termos e expressỏes usadas pelos Guarani ocupantes da área entre o oeste do Paraná, o noroeste do Rio Grande do Sul e o nordeste da Argentina na primeira metade do século XVII. Montoya viveu na Redução de Nossa Senhora de Loreto, no Baixo Parapanema e circulou pelas áreas do Alto Uruguai para onde os indígenas transmigraram depois das incursões das Bandeiras Paulistas. 
'ya gûâ Gûâ, Gûâ Gûâ' = 'listado, pintado'; 'ya gûâ Gûâ, Gûâ Gûâ' = ‘axedrezado' (La Salvia e Brochado, 1989, cf. Montoya op. cit.).

Tendo em vista de que a iconografia indígena é uma atividade simbólica, permeada de significados culturais que dizem respeito a uma sociedade em particular, podemos inferir, através da analogia etnogrática, que o mesmo ocorria com as expressões artísticas de grupos pré-coloniais. Isto nos leva a considerar que a arte gráfica Guarani, visível nos recipientes cerâmicos, envolvia um sistema de signos que comunicavam conteúdos e que eram comuns a todos os membros do grupo. "De acordo com Sahlins (1989), os signos e os seus significados estão sempre relacionados às pessoas que os produziram e a outros signos que fazem parte do mesmo contexto específico. Portanto, eles constituem-se de fragmentos de uma determinada realidade social, pois são uma construção desta não possuindo um significado por si, na medida em que este é construído e reavaliado a partir do contexto, de acordo com os interesses e valores dos seus executores " (Silva, 1992: 160).

Trabalhos etnográficos, como os de Ribeíro (1986), Müller (1990), Lagrou (1991), entre outros (ler Grafismo Indígena, Vidal organiz., 1992), demonstram os significados dos signos gráficos e atestam a origem mítica dos motivos pictóricos. Nos trançados Kayabí aparece uma figura antropomórfica graficamente expressa por um ' $\mathrm{H}$ ' maiúsculo, representando um personagem mitológico designado 'tana', 'tanga' ou 'taangap'. A figura ' $\mathrm{H}$ ' para este grupo significa "sobrenatural, gente". Procurando interpretar as manifestações gráficas no corpo mitológico e à luz do "foco dominante" de sua cultura - a atividade guerreira, Ribeiro descreve um ritual no qual um boneco de palha com forma humana representa um 'añang' (espírito): "(...) o 'añang' - boneco de forma humana pode simbolizar entes mitológicos, antropomorfo e zoomorfo, (...), e que acredito estejam representados graficamente nos motivos de trançado Kayabí pelo padrão 'taangap' e pelo sapo 'kururu'. Representaria, ainda, o inimigo capturado a ser decapitado. Construído em forma animal - sapo, onça - simbolizaria bichos tornados gente, que o herói mítico reuniu e que vieram a ser tribo Kayabí (1986: 278). 

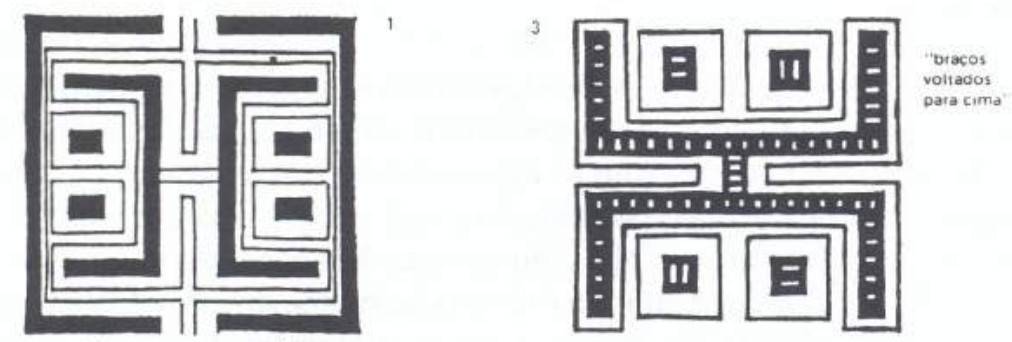

"O pai rodeando o fitho"

2

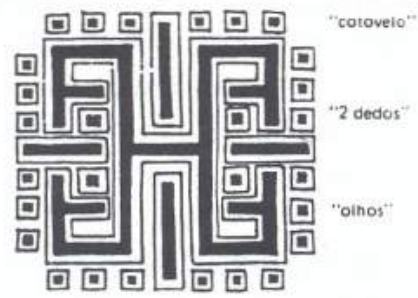

Pr. II. Esquematizaçâo de padrōes de trançado. 1. Taangap ta'it: sobrenatural, criança. 2. Taangap faña'ip: gente, dedos esticados, garra. 3. Sapo kururu. (Ribeiro, 1986: 269)

O elemento simbólico da figura antropomórfica, de origem mítica, ocorre também entre os Asuriní, grupo da mesma filiaçāo lingüística dos Kayabí. O 'tayngava' é o boneco antropomórfico no ritual xamanístico 'maraká', mas também o elemento básico dos desenhos geométricos denominados pela mesma palavra. "A 'grega' nos Asuriní, cujo nome foi tomado da forma da figura antropomórtica do ritual 'maraká' é usada por esta sociedade para expressar a noção de imagem de todas as coisas que representa, princípio constitutivo do ser uno, vivente, possuidor de 'ynga' cujo protótipo é o homem. Daí a noção de imagem se equacionar à forma antropomórfica. Na mitologia, os heróis criadores são humanos; os animais têm forma humana e os espíritos atuais são antropomórficos. Dizem os Asuriní, a respeito destes seres, que todos eram 'avá' (gente, humano) no passado mítico. O homem, portanto, está no centro do pensamento Asuriní: o homem é a imagem do ser. 'Tayngava'" (Müller, 1990: 250). 
Sob esta perspectiva e considerando que não há informações etnográticas sobre o conteúdo simbólico dos signos gráficos Guarani, é que procurei, no corpo mítico desta cultura, uma provável equivalência entre os desenhos pintados nas vasilhas cerâmicas e elementos mitológicos.

\section{Signos gráficos e mitos guaranis: tentativa de interpretação}

Considerando a relação entre mitos e signos gráficos mencionada anteriormente, e ainda que a interpretação de narrativas míticas é capaz de revelar inúmeros aspectos do ethos ${ }^{4}$ de uma sociedade de onde elas provém, como o seu pensamento, a sua concepção de existência, do cosmos, a maneira de estar no mundo, de relacionar-se com ele e com os homens, é que procurei os mitos como recurso, instrumento de decodificação do significado dos desenhos geométricos presentes na cerâmica Guarani. ${ }^{5}$

Entre as pesquisas mais significativas desenvolvidas no interior das sociedades Guarani, encontram-se os trabalhos de Nimuendaju, Cadogan e Shaden que, ao longo do século contribuíram muito em registros sobre a vida destes índios (Vietta, 1992).

Os mitos levantados para esta pesquisa consistem em narrativas compiladas por Cadogan em 'Ayvu Rapyta' (1959) e por Nimuendaju, em As lendas da criação e destruição do mundo (edição brasileira publicada em 1987). León Cadogan, nesta obra, reuniu uma coletânea de mitos que faziam parte das tradiçôes secretas dos Mbya paraguaios -

4 Conforme Geertz (1978: 141) "(...) os aspectos morais (e estéticos) de uma dada cultura, os elementos valorativos, foram resumidos sob o termo 'ethos'."

5 Os mitos "(...) são os moldes necessários que definem, nutrem e reorganizam constantemente as condutas e os comportamentos, as idéias e os ideais de uma sociedade, seja qual for ela. Eles são como espelhos que refletem para esta comunidade sempre singular não somente os moldes e os arquétipos passados, mas também uma realidade de uma outra ordem do que o real no qual mergulham os homens. Este último é, de certo modo, factício, sempre em recomposição em relação ao primeiro que o informa e o reconstrói sem parar. Deste ponto de vista, os mitos têm como função decisiva a de acossar e de reativar as energias da comunidade, as suas intenções, sempre sujeitas à esclerose e, mais particularmente ainda, a de transmitir, de recordar e de reforçar, por meio da palavra e junto à comunidade, o que são seus valores, suas normas de conduta, individuais e comunitárias" (Samain, 1984/85: 234-35). 
parcela Guarani - considerados capítulos "esotéricos", fundamentos da religião. Sua investigação desenvolveu-se entre o final da década de 1940 e início de 1950 entre os Mbya-Guarani de Guairá, auto-denominados de 'Jeguakáva Tenonde Porangue i'. Nimuendaju, por sua vez, conviveu intensamente com os Apopocuva, grupo que compõe a parcela Ñandeva-Guarani, que se deslocava pelo Mato Grosso, Paraná e São Paulo, entre 1905 e 1913. Neste período registrou o universo religioso destas sociedades, documentando narrativas míticas.

Quando nos referimos aos Mbya, Nandeva e Caiová, estamos tratando de parcialidades distintas falantes da língua Guarani. Aqui reside uma problemática relativa à filiação étnica do material arqueológico relacionado à cultura Guarani.

Brochado (1980), conjugando os dados arqueológicos com os etno-históricos - a partir das descrições dos cronistas dos séculos XVI, XVII e XVIII, vincula a Tradição Tupiguarani com a cerâmica produzida pelos Tupi-Guarani históricos, propondo que a área de dispersão da tradição arqueológica corresponderia, em parte, à área cultural TupiGuarani (grupos pertencentes ao tronco lingüístico Tupi). Avançando nesta problemática, o mesmo autor (1984) desenvolveu um modelo no qual estabeleceu uma origem comum para a indústria cerâmica Guarani e Tupi (especificamente Tupinambá), denominada Tradição Polícroma Amazônica. Esta Tradição teria difundido-se em forma de pinças, a partir da região próxima da desembocadura do rio Madeira, na Amazônia Central há, aproximadamente, 1500 a.C. Uma das rotas, que expandiu-se primeiro nas regiões do rio Madeira e Guaporé, passando para o Paraguai, Paraná e subindo ao encontro da outra expansão - que vinha do norte e nordeste para o sul ao longo da costa atlântica - corresponderia aos Guarani.

Com base neste modelo, podemos relacionar a cerâmica arqueológica pertencente à Tradição Tupiguarani encontrada nos atuais territórios do nordeste da Argentina, do sul e sudeste do Paraguai, do noroeste do Uruguai e do sul do Brasil, além do Mato Grosso do Sul e sul de São Paulo aos grupos falantes da língua Guarani. Presume-se, a partir das datações radiocarbônicas mais antigas de sítios arqueológicos (no Alto Paraná com $80 \pm 100 \mathrm{AD}$ e no Rio Grande do Sul, rio Jacuí, com $150 \pm$ $\mathrm{AD}$, in Brochado 1984: 410-14) que a ocupação da área situe-se em torno dos últimos 2.000 anos. 
As pesquisas arqueológicas, portanto, dizem respeito a um Guarani genérico. Os resultados dos trabalhos das últimas décadas não possibilitam a identificação de parcialidades diferenciadas.

Esta problemática é abordada por diversos pesquisadores quando referem-se a elementos que são comuns a todos os Guarani. Shaden (1962: 9) comenta que "à unidade lingüística daquelas tribos meridionais corresponde relativa unidade cultural"; Meliá (1981: 21) escreve sobre a unidade lingüística e cultural evidenciada pelos portugueses e espanhóis no século XVI, apesar de suas diferenciações nos dialetos e nas nucleações regionais autônomas e sugere que esta unidade cultural permite que se levante hipóteses a partir do sistema Guarani como um todo. Vietta (1992: 16) coloca que, "devido à unidade cultural evidenciada entre os vestígios materiais analisados pelos arqueólogos, bem como as várias identificaçōes registradas pelos cronistas, para os grupos que dispersavam-se pela região, parece impossível, ou pelo menos bastante difícil separar parte da história das três parcelas Guarani reconhecidas atualmente".

É oportuno ilustrar esta questão com um exemplo etnográfico. Vidal (Vidal e Silva, 1992), analisando a arte de cada subgrupo Kayapó e as variações que cada um introduziu ao longo do tempo através de seus artistas, constatou que estas são responsáveis pela definição de um estilo próprio a cada subgrupo, que possibilita tanto identificá-lo em sua singularidade, quanto de demonstrá-lo parte da tradição Kayapó.

Avançando nesta perspectiva, observamos a afirmação de Cadogan (1959) de que não há dúvidas quanto à origem comum da religião das diferentes parcialidades, cujos mitos foram recolhidos e analisados por diferentes investigadores. "Y permite deducir que los versos sagrados de 'Ayvu Rapyta' y los demás capítulos "esotéricos" de los textos míticos de los Jeguakáva - pletóricos de poesia y de filosofia - no sean de propriedad exclusiva de esta parcialidad; siendo de presumir que otras naciones guaraníticas que hayan podido, como los Mbya del Guairá, mantener sus tradiciones y lengua libres de influências exóticas, conserven tradiciones similares" (p. 189). O mesmo autor, comparando os anais religiosos dos Mbya com os dos Apopokúva, segundo Nimuendaju, tece considerações sobre a sua semelhança. Por outro lado, Egon Shaden (in Cadogan, 1959) sobre os Caiová (Avá Chiripá, vizinhos dos Mbya de Guairá), coloca que existem grandes diferenças entre seus mitos e os dos Mbya. Cadogan (op. cit.), entretanto, recolheu o depoimento de um Chiripá mestiço que assegurou que as tradições secretas dos Mbya 
constituem também a base da religião dos Chiripá, o que concordam dirigentes Mbya (as diferenças se limitariam às orações e cantos). Mais tarde, porém, lideres Chiripá convenceram Cadogan de que existem realmente diferenciaçōes significativas entre as tradições, mitologia e língua de ambas parcialidades.

Esta realidade torna a interpretação do significado dos desenhos geométricos pintados nos recipientes cerâmicos de um Guarani pré-colonial genérico a partir das narrativas míticas um tanto perigosa e frágil. Mas, na situação em que encontram-se as pesquisas arqueológicas, parece-me o caminho mais provável de ser trilhado.

Outra questão, também polêmica, é a lacuna temporal existente entre a datação do material arqueológico - compreendida nos últimos 2.000 anos - e o período em que foram reunidas as narrativas míticas primeiros cinqüenta anos do século XX. Este aspecto pode ser relativizado considerando o lugar que ocupa a arte em certas sociedades indígenas: esta "(...) se apresenta estática por longos períodos de tempo, porque relacionada a uma trama de significados sociais e religiosos que ela ajuda a preservar" (Vidal, 1984/85: 410-11). Egon Shaden (in Cadogan, op. cit.), com relação aos mitos registrados por Cadogan, avalia que os índios Mbya de Guairá parecem conservar as suas tradições sem alterações provocadas pelo cristianismo da época das missões jesuíticas e mais recente.

Arte e universo religioso, elementos indissociáveis nas sociedades indígenas, parecem ocupar um lugar significativo no que diz respeito à manutenção da etnia. Segundo discorre Ribeiro (1986: 285), o cultivo do artesanato ancestral, símbolo visível de etnicidade e singularidade, é fundamental para a preservação da identidade étnica. "Isto porque, codificado em representaçōes gráficas, ele ajuda a guardar a memória da herança cultural e transmiti-la às novas gerações."

A leitura dos mitos Mbya e Ñandeva foi orientada na busca de elementos que pudessem, de alguma forma, relacionar-se aos padrões de desenhos das vasilhas ou fragmentos destas reunidos. Para isto, em função de que estes são geométricos e abstratos, procurei referências mitológicas que remetessem a elementos formais dos motivos. Isto é, pretendendo encontrar a equivalência entre elementos mitológicos e gráficos, busquei uma relação de semelhança entre forma e referente. $\mathrm{O}$ referente aqui é entendido como o objeto do mundo real que é representado e que pode ser simbolizado. 
Dentre a coletânea de narrativas míticas selecionadas, somente em duas encontrei a possibilidade de realizar a relação proposta.

A primeira, registrada por Nimuendaju (op. cit.), diz respeito à criação e destruição da terra em dois capítulos: 'Inypyrú' (O Princípio, I) (p. 143/151); ‘Guyraypoty' (lenda do dilúvio, II) (p. 155-56) (anexos 1 e 2). Nestes mitos aparece a "cruz de madeira", uma viga colocada no sentido leste-oeste e, sobre esta, uma outra no sentido norte-sul, que representa a "escora da terra" ('yvy-itá'). ${ }^{6}$ Nimuendaju (op. cit. p. 67-68) transcreveu a lenda do dilúvio de 'Guyrapoty' em sua versão original e parte dela corresponde ao que vem a seguir:

"(...) antes de criar a terra, 'N̄anderuvuçú' fez a 'yvy-itá', a escora da terra. Colocou u ma viga no sentido leste-oeste, e outra, por cima, no sentido norte-sul. Pisou então sobre o ponto de cruzamento deste 'yvyrá joaçá recoypý' (cruz eterna de madeira) e encheu os quadrantes de terra (I.I.). Quando a terra tiver que ser destruída, 'Nanderyqueý' (I. XLII) tomará a extremidade oriental do braço inferior da cruz e o puxará lentamente para leste, enquanto o braço superior permanecerá em sua posição original. Com isto, a terra perde o seu suporte ocidental. Ao mesmo tempo, um fogo subterrâneo ('yvý ocái') começa a devorar o subsolo a partir do bordo ocidental da terra; um pouco adiante, suas labaredas alcançam a superfície, e o trecho que ficou atrás desmorona com estrondo ('yvý oá'). De início lenta, depois cada vez mais rapidamente, a destruiçăo avança de oeste para leste.

'Guyrapotý' caminhou então com seus "filhos" para o leste, lentamente, em direção ao mar. (...).

Passados os quatro anos veio o dilúvio ('y ojaparó'), isto é: a água do mar ergueu-se como uma muralha e, inundando a serra do Mar, rolou ('ojaparó') sobre a escora incandescente da terra, para arrefecê-la-pois ‘N̄anderuvuçú' edificaria sobre ela um mundo novo (G. IX.). (...).

Como pode-se observar a "escora da terra" está representada na "cruz" que, por sua vez, simboliza a "escora da terra". Há uma relação de semelhança formal entre o referente - a "cruz' do mito - com o traço distintivo do padrão de desenho onde aparece este elemento (Figura I).

6 O mito de criação do mundo para os Mbya, segundo relata Cadogan (op. cit. p. 28, 29), é outro: o verdadeiro Pai Namandu, o primeiro, com a base de sua vara começou a formar a terra e, com cinco palmeiras eternas que criou, assegurou a morada terrena. 

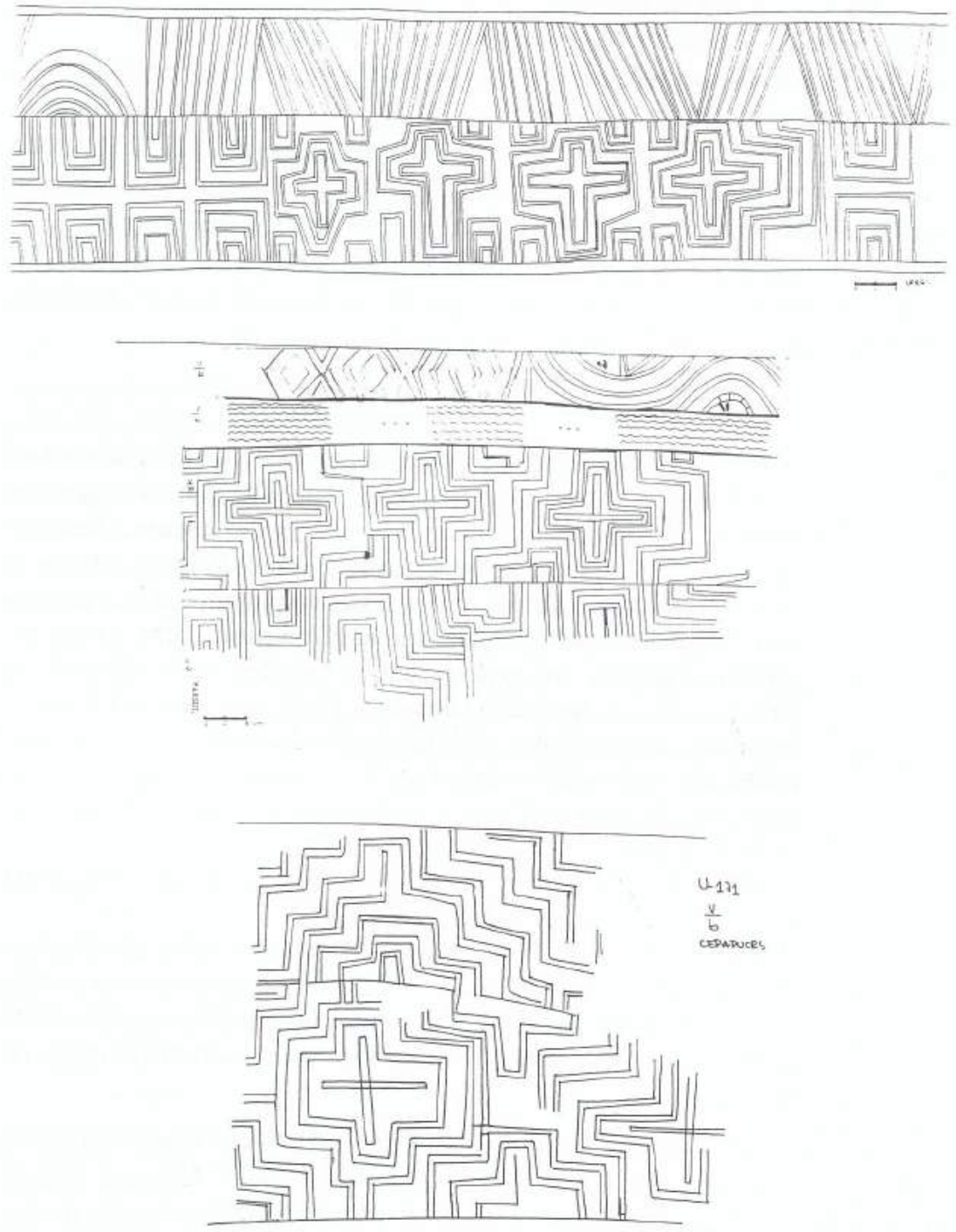

FIG. I 


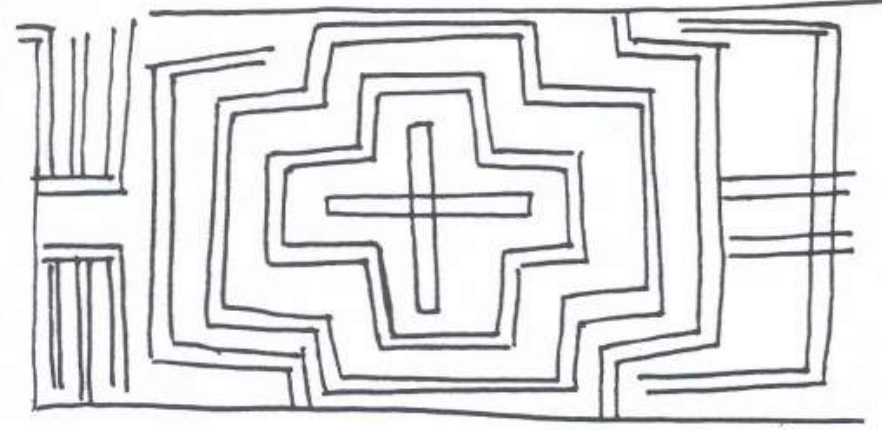

A 'yvy-itá' pode estar representada graficamente no motivo pintado nas vasilhas cerâmicas Guarani pré-coloniais onde o elemento central do padrão geométrico é a cruz.

É interessante salientar que este signo gráfico aparece nos 'cambuchís', grandes recipientes cerâmicos usados para armazenar e servir bebidas aleoólicas nas festas e depois utilizadas como urnas funerárias. Estes 'cambuchís' ocupavam um lugar socialmente determinados e, provavelmente, eram imbuídos de um significado simbálico.

A segunda possibilidade de interpretação do signo gráfico pintado está apoiada, num primeiro momento, em informações sobre os próprios Guarani e na analogia etnográfica e, num segundo, na relação com o mito.

Entre os Mbya-Guarani, os cestos poderiam ser decorados com o trançado sarjado, de cor escura, denominados 'yeguá mbói' e 'pará mbói', traduzidos como adornos ou emblemas de serpente (Noelli, 1993: 205, conforme Cadogan, 1961). Na definição de trançado cruzado em diagonal ou sarjado, Ribeiro (1987: 318) identifica três padrões, entre os quais o "casa de abelhas" e o trançado marchetado, que compõe figuras geométricas (losangos, chevron, gregas, ziguezagues, etc.).

Se empregarmos a analogia etnográfica, veremos que para os Asuriní o desenho chamado 'ehiraimbava' - padrão losangular - está relacionado ao favo de mel ('ehira $=$ mel) $($ Müller, 1990). Montoya registrou a expressão ‘cabati rãmy', 'ayapó yapepó', que significa pintar a panela ao modo de alvéolos de vespas. A relação está entre o padrão de trançado sarjado nos cestos Mbya-Guarani x padrão de trançado sarjado "casa de abelhas" $\mathrm{x}$ panela pintada com desenhos semelhantes aos alvéolos de vespas x 'ehiraimbava'. 




'Ehiraimbava'

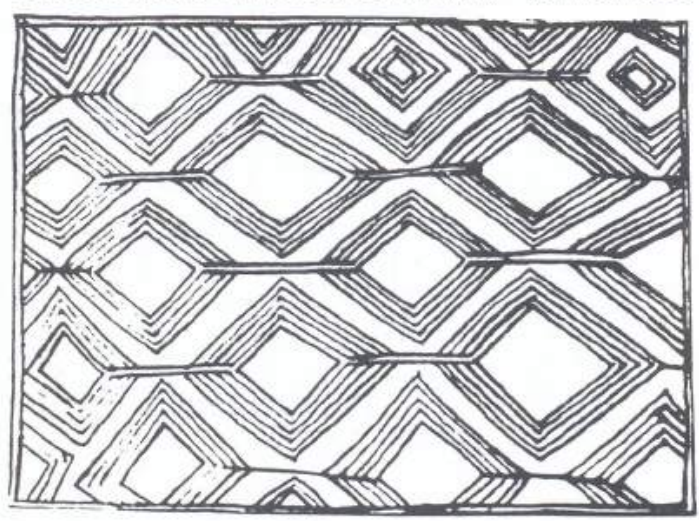

'Ehiraimbava' (Vidal. Müller 1986: 142)

Indo mais além na analogia, agora com os Kaxinawá (Lagrou, 1992: 159), o losango é responsável por um dos motivos básicos do repertório de desenhos (Fig. VII): "o 'txede bedu' (olho de maracanã) (às vezes chamado 'dunu kate' (dorso da cobra) ou 'dunu mapu’ (miolo da cobra)), que é constituído por uma cadeia de losangos cujas pontas se tocam, ou com um espaço entre as pontas e triângulo entre cada losango. O 'txede bedu' completo tem um ponto no meio do losango e um pequeno triângulo no interior do triângulo maior. As linhas que formam o triângulo sempre tocam a beira da faixa. Se não fosse cortado pelos limites da faixa, o triângulo se duplicaria em losango e o motivo mudaria para outro: o 'xapu buxe' (semente de algodáo).

Conforme a autora, o 'xapu buxe' tem a forma de um favo de mel, mas representa a semente de algodão. Aqui não há semelhança formal entre o desenho e o seu referente. Portanto, atribuir um significado ao padrão losangular Guarani relacionado aos alvéolos de vespas, segundo verbete documentado por Montoya, é uma hipótese que pode ser contestada.

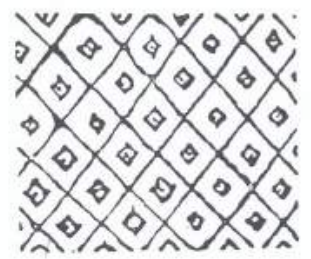

O 'Xapu buxe' (Lagrou, 92: 159) 
QUADRO COMPARAT IVO

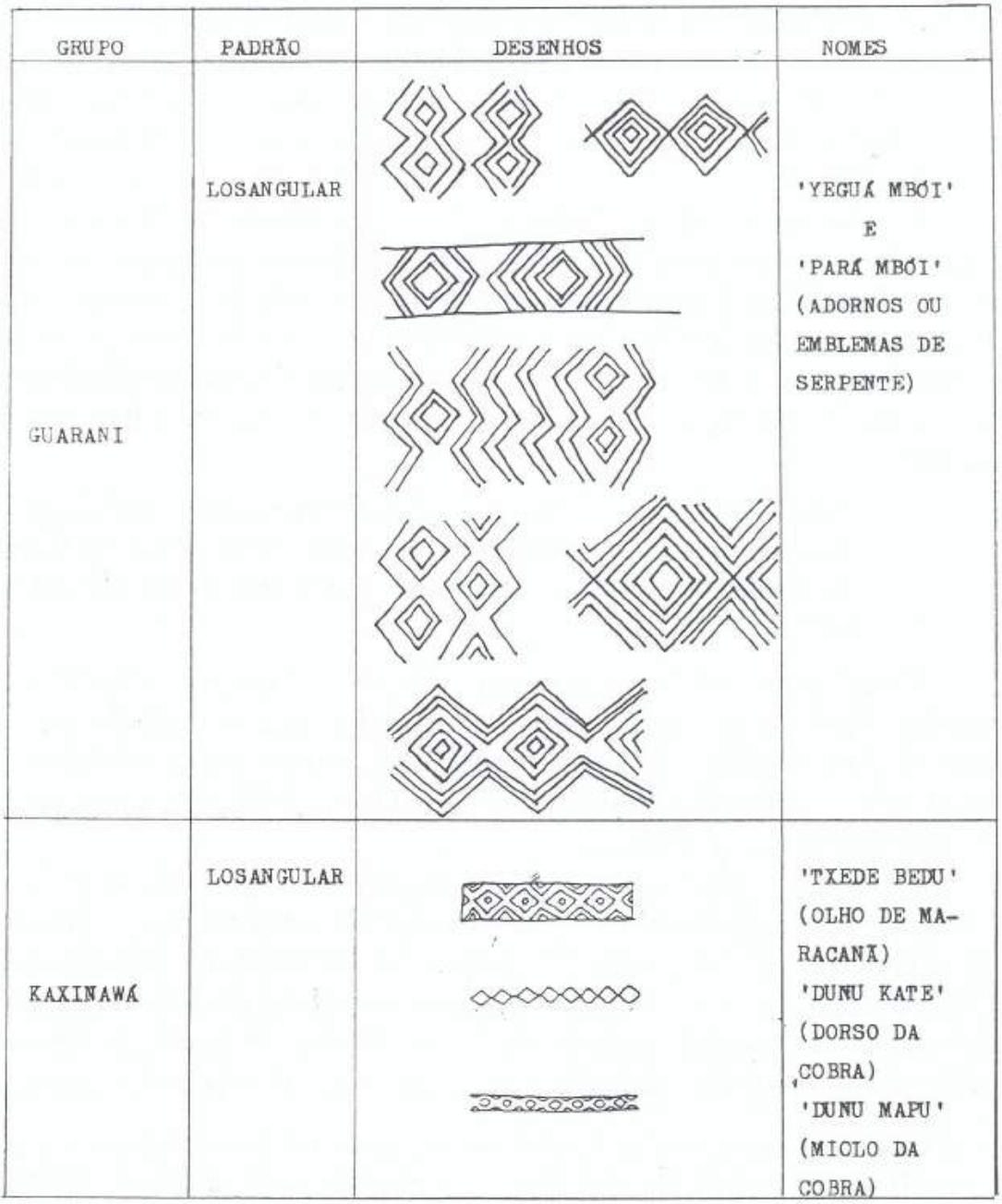


Uma outra possibilidade é procurar relacionar o padrão de trançado sarjado marchetado, no qual o losango está presente, com o padrão losangular dos desenhos Kaxinawá. A relação se estabelece entre padrão sarjado 'yeguá mbói’ e 'pará mbói' (adornos ou emblemas de serpente) $\mathrm{x}$ 'txede bedu' (olho de maracanã), 'dunu kate' (dorso da cobra), 'dunu mapu' (miolo da cobra) x padróes losangulares pintados na cerâmica Guarani (Fig. II).

O referente mítico que poderia estar representado nos desenhos da Figura II, tomando como base para esta relação a informação sobre o motivo decorativo dos cestos Mbya e a analogia com os signos gráficos Kaxinawá e seus significados, encontra-se no mito A Primeira Terra ('Yvy Tenonde', Capítulo III) dos Mbya-Guarani de Guairá (Cadogan, op. cit. p. 28-33). Nele aparece uma referência à serpente ('ñandurié') (p. 29):

"El primer ser que ensució la morada terrenal fué la víbora originaria; no es más que su imagen la que existe ahora en nuestra tierra: la serpiente originaria genuina está en las afueras del paraíso de nuestro Padre".?

Comparando os dois referentes míticos - a "escora da terra" e a "cobra" - percebemos que a semelhança formal com o traço distintivo do padrão de desenho - a cruz e a cadeia de losangos respectivamente ocorre mais visivelmente no primeiro, facilitando, portanto, a revelação do seu significado simbólico.

Quanto à segunda correlação, o excerto do mito onde aparece a cobra não ajuda muito no esclarecimento sobre a representação gráfica do referente (do elemento real que pode ser simbolizado e representado). $\mathrm{O}$ elo de ligação provavelmente encontre-se no significado do padrão ornamental do trançado sarjado de cestos Mbya, composto de figuras geométricas: adornos ou emblemas de serpente. A expressão 'yapepó

7 A serpente resurge no mito da Nova Terra ('Yvy Pyaú'). Segundo Cadogan (op. cit. p. 34) "'Yvy Tenonde', la primera tierra (...) fué destruída por el Diluvio (Capítulo VI) despues de haber ascendido a los Paraísos todos los seres que la poblaban, los virtuosos en forma humana, y los pecadores meta morfoseados en seres irracionales. Crea da 'Yvy Pyaú', la nueva tierra, la que habitamos, em reemplazo del mundo destruído (Cap. VII), fué poblada de imágenes de los habitantes de 'Yvy Tenonde'. Como puede colegirse del contexto la 'víbora ñandurié', el insecto acuático ' $y$-amaí', el saltamontes, la perdiz grande y el armadillo no son seres humanos que sufrieron la metempsicosis, sino aparecieron ya en su forma actual en la primera tierra." (destaque da autora) 
yacaré', traduzida como panela pintada conforme o couro do jacaré por Montoya, teria alguma relação com a representação gráfica da cobra? Neste caso poderia haver também motivos geométricos relacionados aos desenhos do couro da cobra e do jacaré.

\section{Considerações finais}

Nesta pesquisa procurei demonstrar que a iconografia pintada na cerâmica dos Guarani anteriores ao contato com os europeus é uma manifestação gráfica que comunica mensagens, que expressa, numa linguagem visual, conteúdos que dizem respeito à cosmologia e mitologia desta sociedade.

Através de uma leitura do repertório de mitos e dos padrões de desenhos geométricos Guarani e buscando uma semelhança formal entre os elementos centrais dos motivos e os referentes míticos, foram levantadas algumas possibilidades de interpretação dos significados simbólicos destas representações. A "escora da terra" ('yvy-itá') estaria representada na "cruz eterna de madeira" que, por sua vez, provavelmente manifeste-se na "cruz" vermelha, traço distintivo do padrão de desenho dos 'cambuchís'. A serpente simboliza o primeiro ser que "manchou", que "sujou" a morada terrena e que encontra-se, agora, fora do paraíso de "nosso Pai" (outros animais que apareceram na morada terrena cumprindo seu papel, também foram para fora do paraíso). Parece-me que a representação do referente mítico - a serpente - no padrão losangular não esteja fundamentada suficientemente. A relação entre expressão (forma) e conteúdo (significado) provavelmente torne-se mais explícita com a informação sobre o trançado sarjado dos cestos Mbya.

Este trabalho caracteriza-se como uma tentativa de interpretação simbólica aos signos gráficos pintados em recipientes cerâmicos Guarani $\mathrm{e}$, por isso mesmo, e em vista das dificuldades que encontramos em resgatar e compreender a rede de significados culturais das sociedades pré-coloniais, há ainda muitos aspectos a serem abordados e investigados. A analogia etnográfica pode contribuir de forma significativa para o avanço das interpretaçōes à cerca da cultura em toda a sua abrangência - material e imaterial - dos grupos humanos não letrados. 


\section{Bibliografia}

BROCHADO J. P. A Tradiçâo Ceramica Tupiguarani na América do Sul. CLIO, dev. C. Mest. Hist., Universidade Federal PE, n. 3, 1980, p. 47-60.

An ecological model of the spread of pottery and agriculture into Easten South America. Tese de Doutoramento, Urbana. Illinois, 1984.

CADOGAN, León. Ayvu Rapyta. Textos míticos de los Mbyá-Guarani del Guairá. Universidade de São Paulo, Fac. de Filos. Ciênc. e Letras, Boletim n. 227, Antropologia n. 5, São Paulo, 1959.

GEERTZ, Clifford. A interpretação das culturas. Rio de Janeiro: Zahar, 1978.

LA SALVIA, Fernando, BROCHADO, J.P. Cerâmica Guarani. Porto Alegre: Posenato Arte \& Cultura, 1989.

LAGROU, Else M. Uma etnografia da cultura Kaxinawá. Entre a Cobra e o Inca. Dissertaçăo de Mestrado, Programa de Pós-Graduação em Antropologia Social, Florianópolis, 1991.

MELIA, Bartomeu. Los Guarani-Chiriguano 1, Nande Reko nuestro modo de ser. La Paz: Centro de Investigación y Promoción del Campesinato, 1988.

MONTOYA, Antonio Ruiz de. Vocabulario y tesoro de la lengua guarani ó mas bien tupi. 1639. Viena: Faesy y Frick, Paris: Maisonneuse, 1876.

MULLER. Regina Polo. Os asuriní do Xingu. História e arte. Canpinas: Ed. da UNICAMP, Série Teses, 1990.

NIMUENDAJU, Curt Unkel. As lendas da criação e destruição do mundo, como fundamentos da Religião dos Apopocúva-Guarani. São Paulo: Hucitec, Ed. USP, 1987.

NOELLI, Brancisco S. Sem tekohá não há teko (Em busca de um modelo etnoarqueológico da aldeia e da subsistência Guarani e sua aplicação a uma área de domínio no Delta do rio Jacuí-RS). Dissertação de Mestrado, PUCRS, 1993.

PROGRAMA para o Salvamento do Patrimônio Histórico-Cultural - Rio Uruguai, Área Machadinho. Relatório, v. 1, tomo 3, PUCRS, Porto Alegre, 88/89.

PROJETO Arqueológico Uruguai; Levantamento de sítios arqueológicos - Barragem Itapiranga, Florianópolis, Tomo I, UPSC, Eletrosul, Florianópolis; Tomo II, UFSC, UNISINOS, Eletrosul; Tomo III, UFSC, PUCRS, Eletrosul, 1985.

RIBEIRO, Berta G. A linguagem simbólica da cultura material. In trodução. Suma etnológica brasileira. Arte india. Edição atualizada do Handbook of South American Indians. RIBEIRO, Darcy (editor) et al., v. 3, Coord. Berta G. Ribeiro. Petrópolis: Vozes, 1986, p. 15-27. (a)

- Desenhos semânticos e identidade étnica: o caso Kayabí. Suma etnológica brasileira. Arte India. Ed. atualizada do Handbook of South American Indians. RIBEIRO, Darcy (editor) et al., v. 3, Coord. Berta G. Ribeiro. Petrópolis: Vozes, 1986, p. 265-86. (b)

- Glossário dos trançados. Suma etnológica brasileira. Tecnologia indígena. RIBEIRO, DarCy Ribeiro (editor) et.al., Coord. Berta G. Ribeiro, v. 2. Petrópolis: Vozes, 1987 p. 314-21.

ROCHA, Everardo. $O$ que é mito. Sãol Paulo: Brasiliense, Coleção Primeiros Passos, 151. 
SAMAIN, Etienne. Reflexōes críticas sobre o tratamento dos mitos. Rev. de Antropologia, v. 27/28, Dept ${ }^{0}$ de Ciências Sociais (Área de Antropologia), Fac. de Filos. Letras e Ciênc. Humanas, USP, 1984/85, p. 233-44.

SANTAELLA, Lúcia. O que é semiótica. São Paulo: Brasiliense, 1990. Coleção Primeiros Passos, 103.

SCATAMACCHIA, Maria Cristina Mineiro. A tradição policrômica no leste da América do Sul evidenciada pela ocupação guarani e tupinambá: fontes arqueológicas e etno-históricas. Tese de Doutoramento em Antropologia Social (Arqueologia), USP, São Paulo, 1990.

SCHMITZ, Pedro Ignácio. Migrantes da Amazônia: a Tradição Tupiguarani. Arqueologia pré-histórica do Rio Grande do Sul, KERN, Arno (org.). Porto Alegre: Mercado Aberto, 1991.

SCHMITZ, P. I., JACOBUS, A. L., ROGGE, J. H., ARTUSI, L., GAZZANEO, M., MARTIN, H. E., BAUUHARDT, G. Uma aldeia tupiguarani. Projeto Candelária. Documentos 04. Arqueologia do RS, Brasil. Inst. Anc. Pesquisas - UNISINOS, São Leopoldo, 1990.

SHADEN, Egon. Aspectos fundamentais da cultura guarani. São Paulo: Difusão Européia do Livro, 1962.

SILVA, Fabíola Andrea. Manifestações artísticas pré-históricas. Um estudo descritivoclassificatório e interpretativo da Arte Rupestre de Serranópolis-Goiás. Dissertação de Mestrado, UFRGS, Porto Alegre, 1992.

VIDAL, Lux. Aspectos da pintura indígena. Rev. de Antropologia, v. 27/28, Dept ${ }^{2}$ de Ciências Sociais (área de Antropologia) Fac. de Filos., Letras e Ciênc. Humanas, USP, São Paulo, 1984/85, p. 409-14.

VIDAL, Lux, MÜLLER, Regina P. Pintura e adornos corporais. Suma etnológica Brasileira. Arte india. v. 3, Petrópolis: Vozes, 1986, p. 119-48.

VIDAL, Lux, SILVA, Aracy Lopes da. Antropologia estética: enfoques teóricos e contribuiçôes (Conclusão). Grafismo indígena. Estudos de Antropologia Estética. VIDAL, Lux (org.). São Paulo: EDUSP, Studio Nobel, FAPESP, 1992, p. 279-93.

VIETTA, Katya. Mbya: guarani de verdade. Dissertação de Mestrado UFRGS, Porto Alegre, 1992. 